\title{
The system of management of innovative potential of economic systems
}

\author{
Mikhail Kostyshak ${ }^{1,{ }^{*}, \text { Larisa } \text { Poletaeva }^{2}, \text { Natalia Ershova }}{ }^{3}$, Ruzanna Sarukhanyan ${ }^{4}$ and \\ Zinaida Petrikova ${ }^{5}$ \\ ${ }^{1}$ Moscow State University of Civil Engineering, Yaroslavskoye sh., 26, 129337 Moscow, Russia \\ ${ }^{2}$ Moscow Aviation Institute, Volokolamskoe highway, 4, Moscow, 125993, Russia \\ ${ }^{3}$ Russian State University of Justice, 69, Novocheremushkinskaya street, 117418, Moscow, Russia \\ ${ }^{4}$ Yerevan Brusov State University of Languages and Social Sciences, 42, Tumanyan str., Yerevan, \\ Armenia \\ ${ }^{5}$ Voronezh State Technical University, Moscow Avenue, 14, Voronezh, 394026, Russia
}

\begin{abstract}
The purpose of the research is to develop a mechanism for managing the innovative potential of a development organization, which is capable to ensure the transformation of real estate objects due to the changes in market needs. The main approaches to the development of innovative potential of economic systems are presented. Efficiency criteria of management of innovation potential of development organizations are formed. A model based on joint use of system and resource and potential approaches to the management of innovative potential of a development organization is formed. The analysis of modern tendencies of development of innovative potential of economic systems, based on rationalization of management of innovative potential of a development organization is conducted.
\end{abstract}

\section{Introduction}

The modern economy is characterized by a constant need for development, expressed in the implementation of various programs and projects aimed at the active adaptation of modern organizations to the changed conditions of economic environment. In the conditions of transformation of market relations and intensive industrial changes as a result of the shift in consumer preferences, development organizations started to play an important role. These organizations are called upon to promptly solve the problems of adjustment of real estate objects to modern requirements or new functional purposes. For the modern Russian economy, which handles the strategic task of transition from the export-oriented raw material model to the innovative one, a change in industrial priorities under the influence of world trends in the formation of the sixth technological order raises the relevancy of the task of effective management of innovative potential of development organizations. To effectively manage innovative potential of a development organization, it is necessary to develop appropriate methods [1].

Effective management of innovative potential of a development organization is possible only with an integrated approach to the process of its formation and development. To ensure

\footnotetext{
*Corresponding author: 2338580@mail.ru
} 
effective management of innovative potential of a development organization, a detailed study of the innovative activity of development organizations, mechanisms for managing innovation projects, development strategies for development organizations that take into account the current trends of globalization and diversification are necessary. The result of these actions should be a set of measures for the effective management of innovative potential of a development organization.

From this perspective, the management of innovative potential of a development organization in the modern economy of Russia as a participant in the market that provides the developing economic systems with the basic assets adapted to their production and economic activities in terms of real estate objects is a relevant scientific task of great economic importance.

The development of the problem of effective use of innovative potential of a development organization is a relatively new scientific area that requires a serious scientific approach that allows developing an integrated system for the development of innovation activities of a development organization, including modeling the resource support of business processes, assessing the possibilities for transforming development objects in accordance with industrial changes in the development of modern economy [2].

\section{Materials and methods}

Under the management of innovative potential of microeconomic-level economic systems, which include development organizations, it is understood the management of the system's capabilities to achieve the set goals through the implementation of innovation projects. At the same time, many researchers characterize the process of management of innovative potential of the economic system as a part of a structure that contains three components: resource - at the entry into the system, transforming - within the system, and resulting - at the exit of the system.

The principles of management of innovative potential of economic systems are based on the basic principles of innovation management, called upon to ensure the efficiency of innovations, including: creation of an atmosphere that stimulates generation, search and development of innovations; a focus of all innovation activities on the needs of consumers; coordination of priority directions of innovation activity with the goals and objectives of the economic system; minimization of the terms of the process of "research - production - sale" without loss of quality of consumer properties of innovations [3].

Among the principles of the direct management of innovative potential of economic systems are:

- the principle of integration, reflecting the unification of the market, science and production;

- the principle of choosing the most effective variant of using innovative potential in terms of economic efficiency indicators;

- the principle of specialization, assuming that innovative potential of the enterprise is accumulated in the units of the enterprise;

- the principle of proportionality and balance, meaning the need to ensure the equality of innovation opportunities of all units;

- the principle of continuity and rhythmicity;

- the principle of parallelism, signifying the advisability to combine in time the independent innovative measures.

Among the specific principles of the management of innovative potential of economic systems, the principles of flexibility, complexity of managerial decisions, and accounting for the uncertainty and creative nature of innovation work are separated out.

The principles of planning of potential are of great importance in the processes of management of innovative potential of economic systems. These principles include: continuity 
of the strategic, operational and current plans; social and economic feasibility of plans; ranking of planning objects; adequacy of the planned indicators; coherence of management plans for innovative potential with the parameters of the external environment; variability and balance of plans; automation of planning processes; provision of a feedback of the planning system and the implementation system of the plans.

On the basis of the revealed principles of management of innovative potential of economic systems, the main approaches to management and trends in the development of innovative potential of economic systems were identified in this study.

The results of the systematization of approaches to management of the development of innovative potential of economic systems are presented in Figure 1.

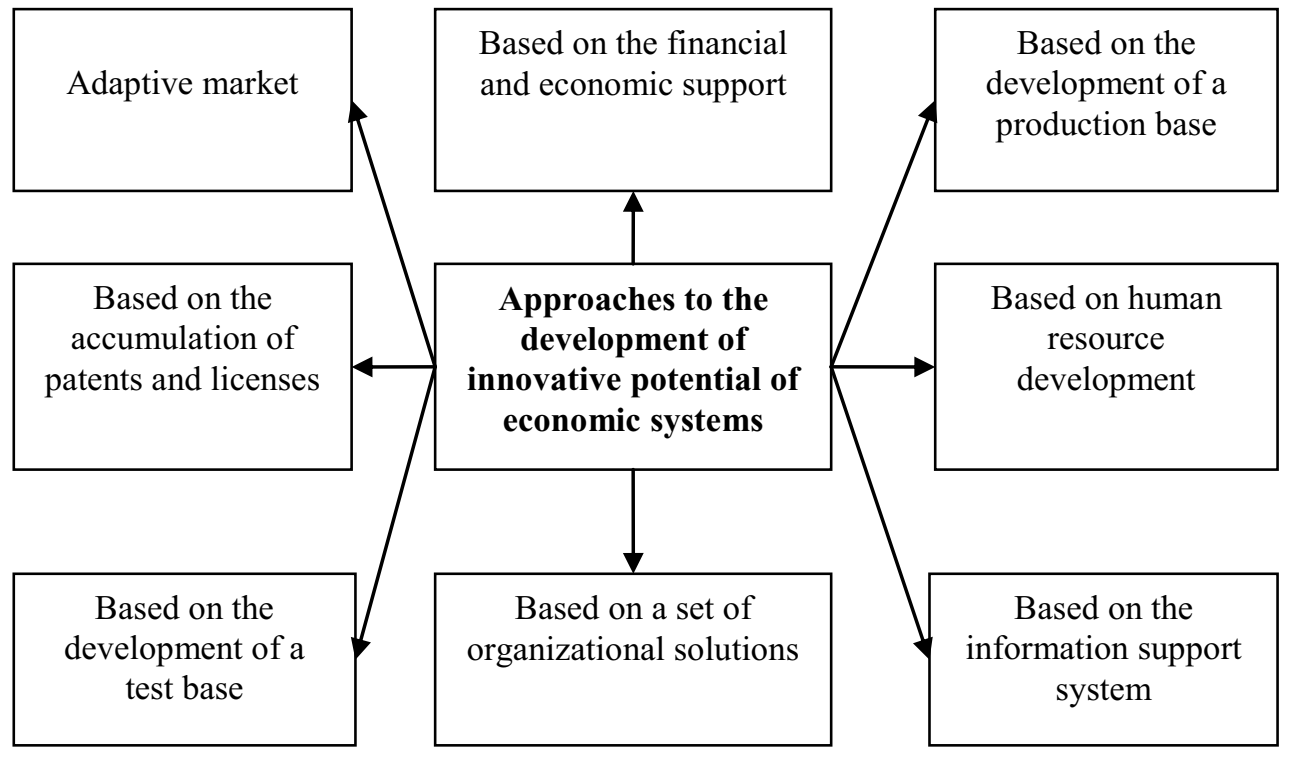

Fig. 1. Basic approaches to the development of innovative potential of economic systems.

The adaptive market approach involves a priority orientation to market trends relative to the initial priorities of the enterprise development that is inherent to the "commutation" firms.

The approach based on financial and economic support involves a power policy of building of innovative potential through the acquisition of intellectual resources, which gives market advantages to the economic system [4].

The approach based on the development of a high-tech production base for the release of innovative products is inherent to "patient" firms. Approaches to the development of innovative potential based on a set of organizational solutions involve the building of innovation activity opportunities through mergers and acquisitions of new enterprises.

\section{Results}

The analysis of current trends in the development of innovative potential of economic systems has shown that the key ones are:

- the development of innovative potential of domestic economic systems is associated with the need to form a new economy - economy of knowledge and high technologies, comparable with oil and gas and raw materials sectors by its contribution to GDP in 2020 and competitive at the world level.

- the development of innovative potential of microeconomic systems is achieved by relative 
growth of: the number of units performing scientific research and development; the number of scientific and technical workers involved in the innovative developments; the volumes of scientific and technical, design and technological, and other types of technological works, etc.

- in the development of innovative potential of economic systems, there is a tendency to reduce budget financing, replaced by private investments, including venture capital investments.

- in recent decades, innovative potential of domestic economic systems is mainly aimed to solve the problems of import substitution.

- the development of innovative potential of economic systems is largely related to the development of the enterprise's innovation infrastructure as a set of interrelated structures that serve and support the implementation of innovation activities.

The development of efficiency criteria is based on an assessment of the prospects for development and use of innovative potential of a development organization in relation to the blocks of a three-dimensional model for studying innovative potential of a development organization (see Figure 4).

The following equation is proposed as particular criterion for management efficiency of innovative potential of development organizations:

$$
k_{a b c}=I R_{a b c} \cdot P_{a b c}
$$

where $P_{a b c}$ - probability of transformation of innovative potential of the development organization into practical results in the field of economic activity $a$ at the level of market services for real estate objects $b$ for the level of radicality of innovations $c$; $I R_{a b c}$ - the potential index of profitability of investing in the innovation activity of the development organization in the field of economic activity $a$ at the level of market services for real estate objects $b$, determined by the combined effect of blocks of innovation potential B1 ... B6, for the level of radicality of innovations $c$.

The following equation is proposed as a group criterion for management efficiency of innovative potential of development organizations:

$$
K_{c}=\sum_{b} \sum_{a} Q_{a b c} \cdot k_{a b c},
$$

where $Q_{a b c}$ - the share of investments in the innovation activity of the development organization in the field of economic activity $a$ at the level of market services for real estate objects $b$ for the level of radicality of innovations $c$.

The following equation is proposed as an integral criterion of management efficiency of innovative potential of development organizations:

$$
K_{0}=\sum_{c} F_{c} \cdot K_{c}=\sum_{c} F_{c} \cdot \sum_{b} \sum_{a} Q_{a b c} \cdot\left[I R_{a b c} \cdot P_{a b c}\right]
$$

where $F_{c}$ - the share of innovation works of the $c$-th level of radicality in the total volume of works of the development organization.

Thus, the established criteria for management efficiency of innovation potential of development organizations take into account the level of compliance of the serviced real estate objects with industrial requirements on the basis of the engineering approach, and also the ability to transform the capabilities of the real estate object to the requirements of other industries on the basis of the reengineering approach. 
Taking into account the developed efficiency criteria, a model of a management system for the development of innovative potential of a development organization was developed, based on the joint use of systemic and resource and potential approaches to the management of innovative potential of the development organization (Figure 5).

At the same time, the main directions of development of innovative potential of the development organization are determined on the basis of the analysis of the flow of potential market orders, as well as the joint effect of macroeconomic and microeconomic factors. When analyzing microeconomic factors in accordance with the research model of innovative potential of the development organization, the focus is on the following assessments of: the areas of economic activity, the current level of market services for real estate objects, the level of innovation used [5].

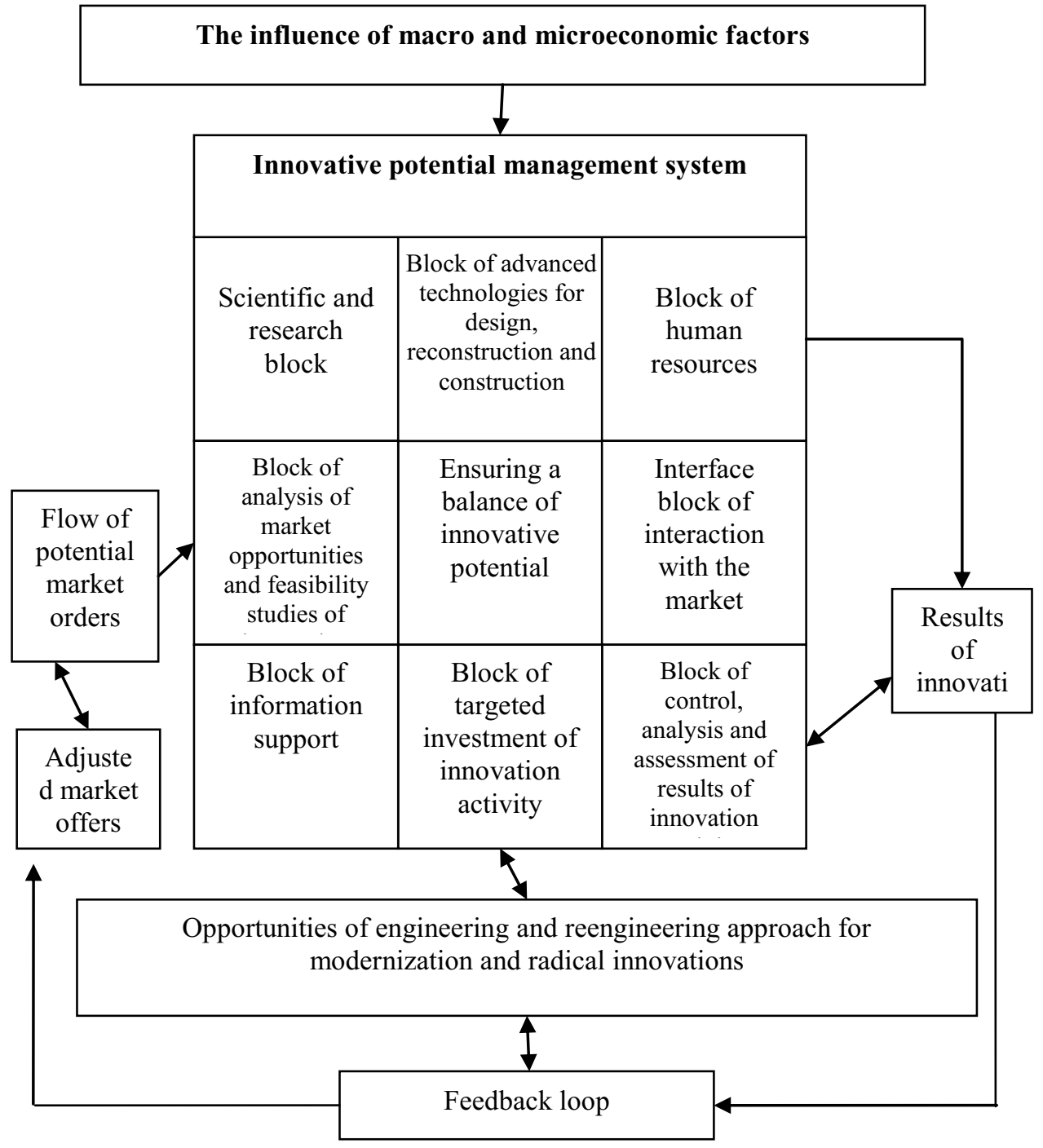

Fig. 5. Model of the management system of innovative potential of a development organization.

Increasing the efficiency of the use of innovative potential of the development organization is achieved by increasing the level of innovative capabilities of the development organization for blocks B1-B8 with a rational distribution and redistribution of innovation resources through 
block B9, while improving the quality of innovation projects of the development organization on the basis of alignment of the interests of all participants in innovation activities, as well as in the organization of the development of innovative potential of the development organization in accordance with changes in the external environment, based on the joint use of the engineering and reengineering approaches of varying degrees of radicality, and also taking into account (through the feedback loop) the market reaction to the results of management of innovation potential $[6,7]$.

Based on the complex of conducted studies, the technology of management of innovative potential of the development organization was determined. This technology is based on ensuring the compliance of the decisions made with current market conditions, allows keeping the state of dynamic balance of existing sources and needs for the use of resources of innovation activity of the development organization, and takes into account the need to improve the structural interrelations between the stages of innovative development of the development organization.

The proposed technology for management of innovative potential of the development organization, with a fixed volume of targeted investments in the innovation activities at a planned time interval and set limits on the share of innovations $\sum_{c} F_{c}<F^{*}$ volume of work of the development organization, are based on the search for maximum densities of joint probabilities $P_{a b c}$ for transforming the innovative potential of the development organization in the field of economic activity $a$ at the level of market services for real estate objects $b$ for the level of radicality of innovations $c$ with a potential index of profitability of investing in the innovation activity of the development organization $I R_{a b c}$ $\left(I R_{a b c} \cdot P_{a b c}\right)$ and the share of investment in the innovation activity of the development organization in the field of economic activity $a$ at the level of market services for real estate objects $b$ for the level of radicality of innovations $c Q_{a b c}$ :

$$
\sum_{b} \sum_{a} Q_{a b c} \cdot\left[I R_{a b c} \cdot P_{a b c}\right] \underset{\operatorname{var}\left(Q_{a b c}, P_{a b c}\right)}{\longrightarrow} \max
$$

Therefore, according to the proposed technology, rationalization of management of innovative potential of the development organization is achieved not only by redistribution of investment resources, but also by an increase in the probability of transforming the innovative potential of the development organization into practical results.

\section{Conclusion}

At the stage of analyzing of market environment for the functioning of development organizations, it is advisable to focus on studying the changes of industry preferences of clients of development organizations. When studying the components of innovation potential of development organizations as an object of management, more attention should be paid to the block of information support, including databases on the components of market conditions and their dynamics.

When using the proposed criteria for management efficiency of innovative potential of development organizations, the accuracy and reliability of determining the probability of transforming the innovative potential of a development organization into practical results in a required area of economic activity at the selected level of market services for real estate objects and the level of radicality of innovations are of great importance. 


\section{References}

1. V. Pukhkal, V. Murgul, M. Garifullin, Procedia Engineering 117, 624-627 (2015)

2. R.S. Golov, V.V. Shilov, S.A. Silantiev, ASEE International Forum, Columbus, 20766 (2017)

3. A. Jones, G. Fallon, R. Golov, European Business Review 12(4), 187-197, doi. 10.1108/09555340010336871

4. A. Bril, O. Kalinina, O. Valebnikova, Lecture Notes in Computer Science 9870, 766775 (2016) doi:10.1007/978-3-319-46301-8_67

5. A.K. Orlov, I.Y. Chubarkina, MATEC Web of Conferences 106, 08015 (2017)

6. I.V. Ilin, A. Lepekhin, A.I. Levina, O.Yu. Iliashenko, Advances in Intelligent Systems and Computing 692, 1306-1314 (2018) doi:10.1007/978-3-319-70987-1_138

7. V. Gasilov, N. Anisimova, I. Provotorov, MATEC Web of Conferences 106, 08035 (2017) DOI: 10.1051/ mateconf / 201710608035 